\title{
How to Manage the Unresponsive Patient
}

\author{
R. A. HITCHINGS and J. LATTIMER \\ Moorfields Eye Hospital, London
}

The long term management of any chronic disease is rewarded with success and failure in varying proportions. Glaucoma is no exception to this general rule. This problem is particularly relevant in the management of chronic glaucoma, for here the ophthalmologist is treating not one but a group of diseases. In all cases, however, the criteria for success are the same-control of intraocular pressure and prevention of (further) visual field loss. Although these two parameters tend to be linked in the minds of most people, this is not always the case. Reference to the patient with progressive 'low tension glaucoma' demostrates this. Even the patient with 'high tension glaucoma' will sometimes lose field despite 'good control' of intra-ocular pressure..$^{1,2}$

With these criteria in mind it can be seen that although two therapeutic goals in the long term management of the glaucomas can exist, the first and major one must be the prevention of (further) visual loss, while the second is 'control' of IOP. Despite this difference in importance, most experience been gained with the latter and it is this that will be discussed after a short section on prevention of (further) visual loss.

Table I. Visual loss despite good control of IOP.

(1) Poor performance on Perimetry (also 'long term fluctuation'3)

(2) Undetected spikes in IOP;

(a) nocturnal

(b) IOP rise when supine

(c) poor compliance

(3) No glaucoma cause for visual loss

(4) Low Tension Glaucoma

\section{Visual Loss Despite 'Control' of IOP}

A commonly recurring clinical problem is in the patient whose visual field continues to progress despite 'good' IOP control. The possible causes are listed in Table I.

An awareness of these possibilities enables the correct management to be undertaken. For those patients who have episodic elevation of IOP with or without good compliance, instruction and/or alternative treatments need to be given.

Those patients who seemingly have 'good' IOP control, even on 24 hour IOP checks (as in the usual patient with progressive Low Tension Glaucoma) then further steps can be taken. These might involve lowering the IOP to subnormal levels (although no study has shown that this approach will slow the rate of visual loss). ${ }^{4}$ Alternative approaches will include the use of drugs to improve visual function without lowering IOP. This approach, while still experimental includes the use of calcium blockers and the use of beta-blockers, but not for their hypotensive effects. $^{5}$

\section{Inadequate IOP Control}

The IOP may be considered 'inadequately' controlled when it runs at a level where (further) visual loss is likely to occur. (And that the rate of such visual loss would be likely to proceed at such a rate that it would inconvenience the patient in his or her lifetime). Clearly the tolerated IOP levels will vary considerably from patient to patient. The patient's age, the IOP level, the likely duration of the hypertension and the health of the eye are just some of the factors to be considered. 


\section{Table II. Difficult Glaucomas}

(a) Buphthalmos (unresponsive to goniotomy)

(b) Glaucoma secondary to inflammation

(c) Glaucoma with aphakia

(d) Glaucoma secondary to vitreo-retinal surgery

(e) Primary open angle glaucoma with failed fistulising surgery

(f) Neovascular glaucomas

There are a number of glaucomas where 'inadequate' control persists despite medical and laser treatment, some of these are shown in Table II.

The patient with inadequately controlled intraocular pressures, as defined above, may be treated in one of two ways (although they are not mutually exclusive). Either the ciliary body may be destroyed in situ, or surgically removed; or, an alternative route be found for aqueous to exit from the eye. As is shown below, many of these patients may be very young, so it seems reasonable to try the latter approach in an attempt to re-establish normal drainage of aqueuous. Our experiences at Moorfields have been largely with this second line of approach. The possibilities of silicone tubes were first investigated 10 years ago and in our initial report, in patients with neovascular glaucoma, we left the tube exposed in the upper fornix. ${ }^{6}$ This approach failed because the end of the tube became buried beneath the conjunctiva; the cross sectional area of the tube in contact with the conjunctiva proved insufficient for adequate aqueous absorption (a problem which may account for the failures seen with the Krupin Denver valve). ${ }^{7}$ The ACTSEB operation described by Schocket ${ }^{8}$ offered a way around this problem, for the tube end was left beneath an inverted size 20 silicone retinal detachment gutter. Our first experiences with this operation were reported in $1984 .{ }^{9}$

\section{Material and Methods}

All patients seen in the glaucoma unit whose IOP was not considered 'controlled' despite maximum tolerated medical treatment, and who had previously undergone (at least) one glaucoma operation were selected for the two piece silicone tube and gutter operation as described by Schocket. ${ }^{8}$ Initially the operative procedure followed was that orginally described. With increasing experience a number of modifications became necessary. These included inserting the tube into the anterior chamber through a cyclodialysis cleft, using Healon in the tube and around the gutter ${ }^{10}$ and, suturing the distal end of the tube to the underside of the gutter, thus preventing fibrous tissue from occluding the end.

After surgery all patients were followed in the Glaucoma Unit and were treated with the appropriate steroid and antibiotic drops. Hypotensive treatment was also given if the IOP was considered to be persistantly 'uncontrolled' ( $v$. infra). A number of patients required reoperation, either because the IOP rose again to uncontrollable levels, because of some postoperative complication or, because of some intercurrent problem not directly related to the surgery.

\section{Results}

Fifty-one eyes of 47 patients were operated upon.

The different diagnoses were as follows:

Buphthalmos: 15 eyes

Primary open angle glaucoma: 7 eyes

Secondary to inflammation: 9 eyes

Glaucoma with aphakia: 7 eyes

Secondary to vitreo-retinal surgery:

Other

2 eyes

11 eyes

These had undergone an average of 2.5 previous glaucoma operations and were receiving, on average 1.9 glaucoma medications.

Table III. Intraocular Pressures in eyes followed for one year or more

\begin{tabular}{cccccc}
\hline Months post op & No eyes & Mean IOPmm hg & (range) & $\%$ IOP $<21$ & $\%$ off medication \\
\hline 12 & 35 & 20.9 & $(8-54)$ & 71 & 51 \\
18 & 27 & 17.6 & $(8-32)$ & 74 & 44 \\
24 & 21 & 18.9 & $(8-45)$ & 76 & 43 \\
30 & 13 & 19.6 & $(6-31)$ & 50 & 62 \\
36 & 6 & 20.0 & $(16-28)$ & 83 & 50 \\
\hline
\end{tabular}




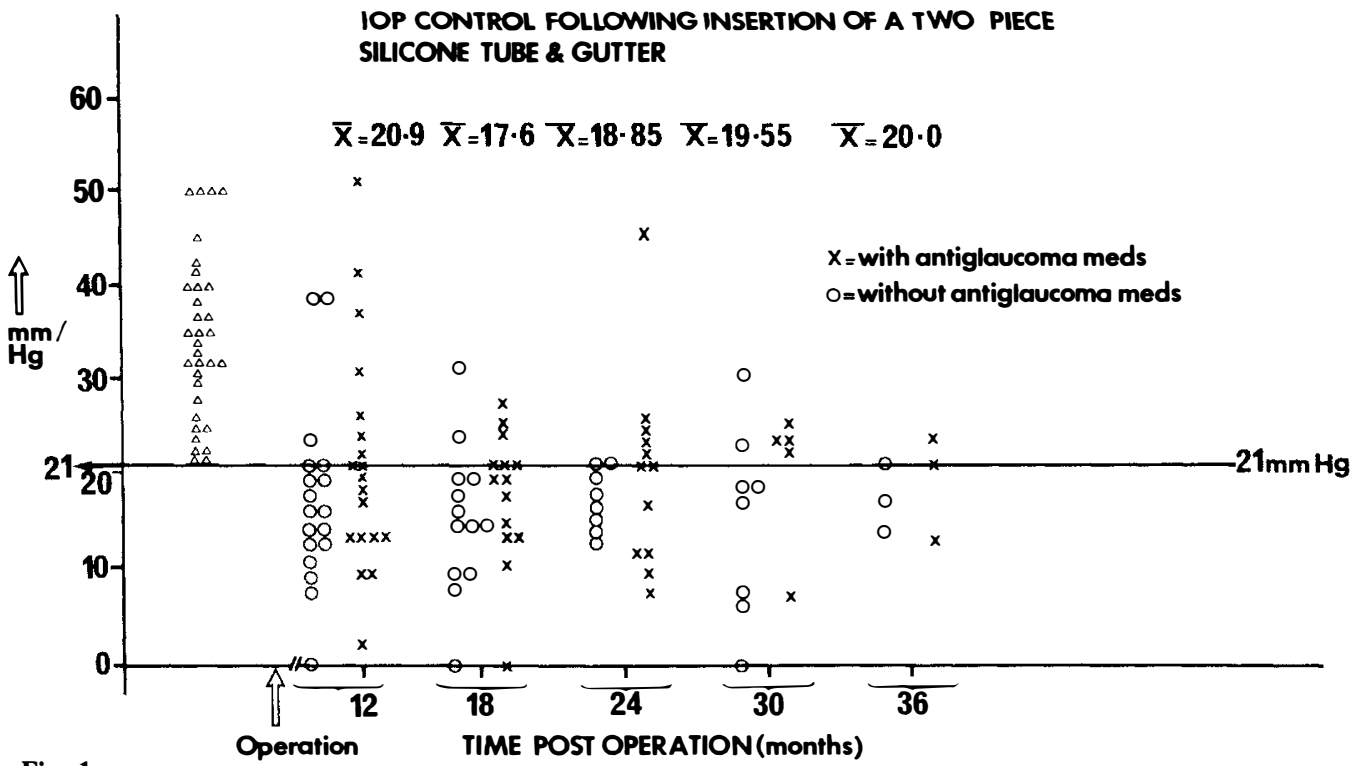

Fig. 1.

The short term results of many of these eyes have already been reported, ${ }^{9}$ this report notes the long term results.

Thirty-five eyes have been followed for one year or more. The IOPs have been set out in Fig. 1. and are summarised in Table III.

Sixteen of the 35 eyes had had one operation and their IOP was 'controlled' on or off antiglaucoma medications. Three eyes had reoperations because of tube exposure. Sixteen eyes required reoperation because of 'uncontrolled' IOP. The majority of these took place in the first three postoperative months. Table IV sets out the timing of these reoperations.

Table IV. Time of reoperation (Revision)

\begin{tabular}{cccc}
\hline $\begin{array}{c}\text { Reoperation } \\
\text { (months post-op) }\end{array}$ & $\begin{array}{c}\text { No } \\
\text { eyes }\end{array}$ & $\begin{array}{c}\text { No } \\
\text { revisions }\end{array}$ & $\begin{array}{c}\text { Joseph } \\
\text { tubes }\end{array}$ \\
\hline $0-3$ & 8 & 9 & - \\
$3-6$ & 2 & 1 & 1 \\
$6-9$ & 4 & 2 & 2 \\
$6-12$ & 5 & 3 & 2 \\
$12-18$ & 1 & 1 & 1 \\
$>18$ & nil & & \\
\hline
\end{tabular}

(The Joseph Tube ${ }^{11}$ was inserted in 5 of the 6 cases after the IOP was uncontrolled despite revision). One eye could have more than one revision.
The long term follow-up achieved after this last operation is shown in Table $\mathrm{V}$.

It can be seen that although the overall numbers are reduced, the proportion of eyes achieving long term control are the same. None of the eyes receiving a Joseph tube have been followed for long enough to be included. These results demonstrate that although there were 'teething troubles' with this technique, it is possible to obtain good IOP control. This view is substantiated by the observation that none of the eyes with less than 12 months follow-up have yet required further surgery.

\section{Discussion}

In this paper the Unresponsive Patient has been categorised as either

(1) a patient whose visual field continues to deteriorate despite 'normal' intraocular pressures,

(2) whose IOP is difficult to bring down to 'normal' levels.

For the reasons discussed earlier we have confined this paper to the latter group. We have presented results that show that it is possible to control approximately 70 per cent of these difficult glaucomas with IOPs greater than $<21 \mathrm{~mm}, 50$ per cent of which were off antiglaucoma medications. It should be remembered, however that 46 per cent of 
IOP CONTROL AFTER LAST OPERATION

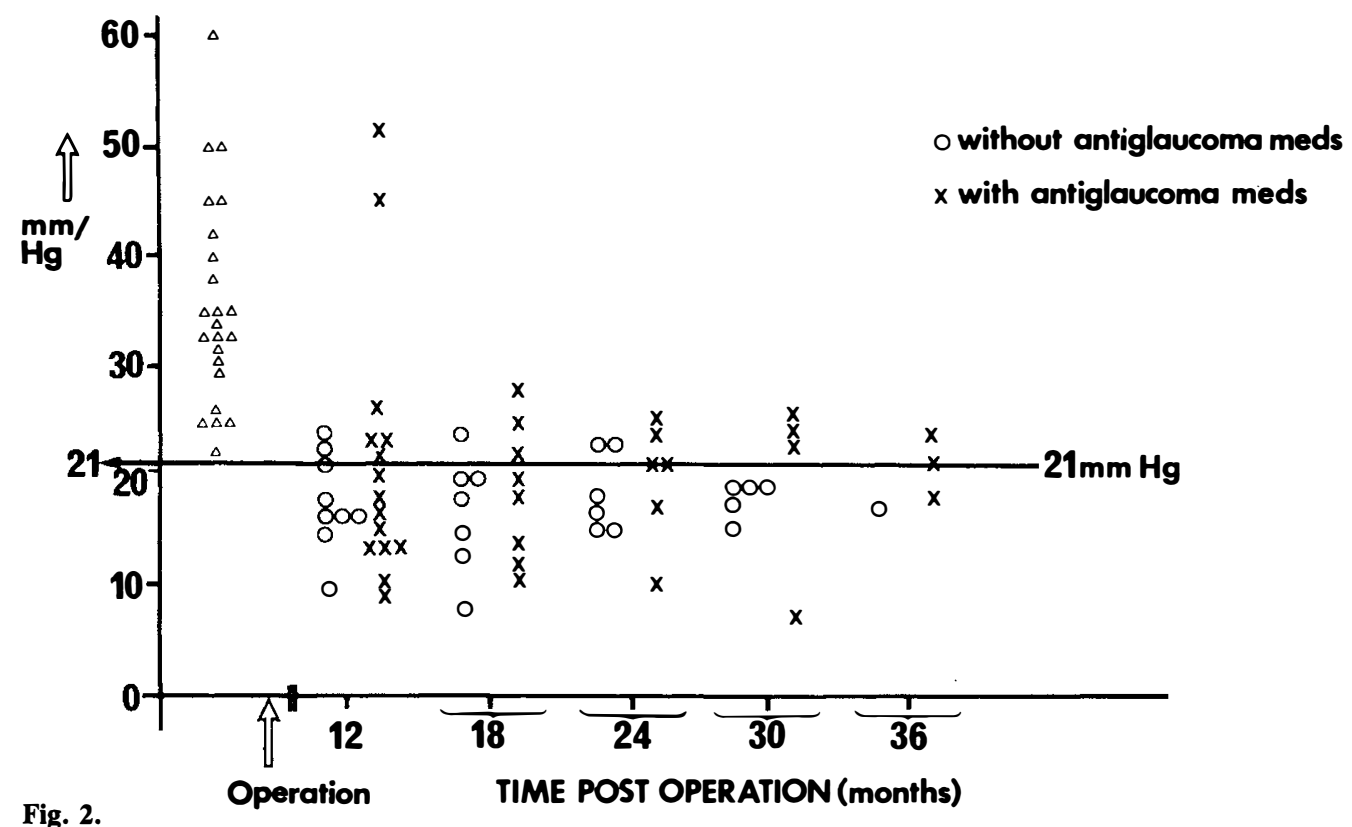

these eyes required more than one operation to achieve this result. In the light of these results it is worthwhile looking at alternative forms of treatment.

There are two theoretical ways of lowering IOP. The first method involves reducing aqueous production. In the context of this discussion this means ciliary body destruction. As a considerable proportion of the patients seen by the authors were young it seemed inappropriate to choose this method if an alternative was available. We have concentrated therefore on the development of a drainage implant.

The system described by Schocket, preliminary results which have already been reported, ${ }^{7}$ was with suitable modifications able to control IOP in approximately 50 per cent of cases without further medications for up to three years and, in another 25 per cent with the use of additional medications. This operation can be said to offer much in the management of the unresponsive patient. Two points are worth discussing. How to overcome the large number of complications and, whether the two piece tube and gutter system as described by Schocket is the best of the 'tube' systems that have been described.

Despite the impressive results in Schockets first paper, the tube and gutter system has a number of serious drawbacks. These include

(1) tube exposure

(2) overdrainage in the initial post operative period

(3) tube corneal or tube iris touch

(4) late failure from tube gutter interface block and insufficient drainage.

These complications lead to revision of the tube in a fair proportion of cases. However these 'tube revisions' were seen mostly in the earlier patients in this series, most revisions were in the first months of the postoperative period and those patients who passed the first follow-up year seemed to be trouble free. It is possible that the one piece tube and plate described by Joseph will reduce significantly the incidence of post operative complications.

The results obtained with this 'two piece' tube and gutter have to be compared with results other drainage systems. Molteno has written extensively on this subject describing long term follow-up of his tube and plate. Our 
Table V. Intraocular Pressure control following the last operation.

\begin{tabular}{cccccc}
\hline $\begin{array}{c}\text { Time from last } \\
\text { operation } \\
\text { (months) }\end{array}$ & No eyes & Mean IOP mm hg & range & \% IOP <21 & \% off medication \\
\hline 12 & 23 & 19.6 & $(8-52)$ & 56 & 39 \\
18 & 16 & 18.0 & $(8-25)$ & 75 & 44 \\
24 & 13 & 18.8 & $(10-25)$ & 61 & 54 \\
30 & 10 & 19.4 & $(7-26)$ & 60 & 50 \\
36 & 4 & 20.0 & $(17-24)$ & $(75)$ & $(25)$ \\
\hline
\end{tabular}

reasons for not using his device were initially because it was available and, latterly because of its cost. To obtain adequate drainage he advocates his 'two plate' system, even this has a smaller surface drainage area than the encircling gutter and, if a thick fibrous tissue capsule develops around the plate it would tend to be insufficient for aqueous absorption. Molteno advocates a complex regime of antifibrotics, however the need for this regime has been questioned ${ }^{12}$ and Molteno limits its use to the fit patient. He feels that the young patient does not scar as extensively as the elderly patient and does not use the regime in these patients. The tendency to scar is, in our experience even more pronounced in the young, yet we find that an antifibrotic regime may be dispensed with. Despite the foregoing remarks it has to be said that Molteno has reported good results with his device (he reported that out of 53 patients given his 'two plate' system who had been followed-up for 6 months to 3 years 43 were cured (with an IOP $<21$ ) while a further 8 were controlled with the same IOP level while taking antiglaucoma medication. The two plate system provides an alternative method of approaching the problem of the unresponsive patient.

Recently 5-Fluorouracil (5 F-U) has been shown to reduce postoperative fibrous tissue formation in the experimental animal and latterly in patients with poorly controlled glaucoma. ${ }^{13}$ As the drug when given topically causes corneal erosions, it has to be given subconjunctivally. The favoured regime is for twice daily injections for one week followed by daily injections. Such a demanding postoperative course is unlikely to be tolerated by the young patient and it is this group that make up the numbers of patients with the excessive fibrous tissue response. Alternative methods of delivery of the drug are being investigated, in an attempt to make a promising approach more acceptable, as are other drugs which inhibit fibrous tissue proliferation.

Molteno's two plate system has a surface area for aqueous absorption of $270 \mathrm{sq} \mathrm{mm}$. The tube and plate used in this paper has an absorbing area double that. The one piece system described by Joseph et al. ${ }^{11}$ can be made with absorbing areas of up to $1200 \mathrm{sq} \mathrm{mm}$. In theory an increase in the area available for aqueous absorption is required either if the fibrous tissue reaction is expected to be very marked (as a result of previous surgery) or if a very low IOP is required in the postoperative period. This latter would be of use in those cases of progressive low tension glaucoma, for which surgery is justified. If lowering IOP has any part to play in the management of the low tension glaucoma patient then the Joseph tube may well be indicated. This approach would be a method of treating those other 'unresponsive patients' outlined at the start of this paper.

\section{References}

${ }^{1}$ Anderton S, Coakes R, Clarke P, Poinooswamy $S$ and Hitchings RA. The nature of visual loss in Low Tension Glaucoma. Sixth International Visual Field Symposium, eds Heijl A and Greve EL, 1984, pp 383-6.

${ }^{2}$ Werner EB and Drance S. The effect of trabeculectomy on the progression of visual field defects. Second International Visual Field Symposium, ed Greve EL, 1976, pp 67-74.

${ }^{3}$ Bebie H, Fankhauser $F$ and Spahr J. Static perimetry; Accuracy and Fluctuations. Acta Ophthalmol. 1976, 54: 339-48.

${ }^{4}$ Abedin S, Simmons RJ and Grant WM. Progressive Low Tension Glaucoma. Ophthalmology. 1982, 89: $1-6$.

${ }^{5}$ Drance SM and Flammer J. Some effects of antiglaucoma drugs on visual function. Glaucoma: 
Applied Pharmacology in Medical Treatment. Grune and Stratten 1984, pp 569-76.

${ }^{6}$ Blach RK, Hitchings RA and Laatikinen L. Thrombotic Glaucoma: Prophyllaxis and management. Trans Ophthalmol Soc UK. 1975, 97: 275-9.

${ }^{7}$ Folberg R, Hargett NA, Weaver JH et al. Filtering valve implant for neovascular glaucoma in proliferative diabetic retinopathy. Ophthalmology. 1982, 89: 286-9.

${ }^{8}$ Schocket SSS, Lakhanpal V and Richards RD. Anterior chamber tube shunts to an encircling band in the treatment of neovascular glaucoma. Ophthalmology. 1982, 89: 1189-94.

${ }^{9}$ Sarkies $\mathrm{N}$ and Hitchings RA. Silicone tube and gutter in advanced glaucoma. Trans Ophthalmal Soc UK. 1984, 104: 133-6.

${ }^{10}$ Sherwood M, Joseph N and Hitchings RA. Complications of silicone tube implant surgery and modifications of technique. Arch Ophthalmol. Inpress.

${ }^{11}$ Joseph N, Sherwood M, Trantas G and Hitchings RA. One-piece drainage system for glaucoma surgery. Trans Opthalmol Soc UK. In press.

${ }^{12}$ Brown RD and Cairns JE. Experience with the Molteno Long Tube implant. Trans Ophthalmol Soc UK. 1983, 103: 297-312.

${ }^{13}$ Heuer DK, Parrish RK, Gressel MG, Hodapp E, Palmberg PF, Anderson DA. 5-Fluorouracil and glaucoma filtering surgery-a pilot surgery. Ophthalmology. 1984, 91: 384-94. 